\title{
Effect of storage environment and period on viability of breadnut (Artocarpus camansi Blanco) seeds in rainforest agroecology, Nigeria
}

\author{
Olasanmi B.
}

Department of Agronomy, Faculty of Agriculture, University of Ibadan, Nigeria.

Author. Email: bunminadeco@yahoo.com.

Accepted $19^{\text {th }}$ April, 2018.

\begin{abstract}
There is need to encourage domestication and utilization of important indigenous tree species in Nigeria by educating the populace about the crops and making their seedlings available for potential growers. Access to seeds and seedlings are associated with seed storage problems which affect the use of many potentially high value indigenous species such as breadnut. However, there is no adequate information on seed handling, storage and seedling production of breadnut in rainforest zone of Nigeria. A study was therefore carried out to investigate the effect of methods and period of storage on viability of breadnut seeds at Ibadan, Nigeria. Some breadnut seeds were stored using refrigerator $\left(4^{\circ} \mathrm{C}\right)$ and open shelf in two different seasons while some were planted immediately after extraction from the fruit (fresh). The seeds in storage were tested fortnightly in 2014 and weekly in 2015 from each batch for viability by sowing in the nursery. Total loss of viability was recorded for breadnut seeds stored for any period using each of the two methods while 67 to $72 \%$ germinability was recorded for seeds sown immediately after removal from the fruits (control) over the two seasons. This indicates that breadnut seeds cannot be stored for up to a week using any of the methods investigated in this study, hence, the need for further investigation to develop a protocol for handling and storage of breadnut seeds.
\end{abstract}

Keywords: Breadnut, breadfruit, germinability, open-shelf, refrigeration, seedling emergence.

\section{INTRODUCTION}

Breadnut (Artocarpus camansi) belongs to the botanical family Moraceae. Breadnut, which is considered as an ancestor of breadfruit (Artocarpus altilis), originated in Papua New Guinea in the Western Pacific region and the Philippines (Roberts-Nkrumah, 2005; Nelson, 2017). It is now grown in West Africa, South and Central America and the Caribbean (Nelson, 2017). Breadnut also known as a katahar and chataigne in Guyana and Trinidad and Tobago is also regarded as a seeded variety of breadfruit (Nelson, 2017). Despite the name, it is not a nut but rather a fruit and it is also sometimes called Maya nut. According to Nelson (2017), breadnuts grow abundantly in the warm, wet climates and they are easy to harvest and store.
Global demands for food, feed, and fiber are expected to double in the next 35 years and in the same timeframe, we face a world of diminishing arable land, extreme weather events, unsustainable fertilizer inputs, uncertain water availability and plateauing crop yields, hence, the need for new innovative approaches to sustainably increase global crop productivity (APS, 2016). According to Roberts-Nkrumah (2005), breadnut has remarkable potential as an alternative food source in the tropics based on its nutritional content and level of seed production. According to Adeleke and Abiodun (2010), breadnut seeds contain appreciable amount of protein, carbohydrate and mineral contents and its oil is rich in unsaturated fatty acid which compare well with those of 
melon seeds, soybean and groundnut oil. Morton (1987) also stated that breadnut is of more value as food than the seedless breadfruit which has lower protein content. Despite the importance of this crop, is can be regarded as a neglected crop as it is not listed among the African orphan crops (AOCC, 2013), hence the need to study its agronomic requirements from the point of raising seedlings in the nursery to harvesting period on the field.

Propagation of any crop and subsequent development depends on the quality of the planting material. However, little is known about the seed physiology of most tropical forest tree species and a large proportion (more than $70 \%$ ) of them produce seeds with recalcitrant or intermediate seed storage behaviour, which are difficult to collect, process and store (Dulloo et al., 2004). Many of these seeds according to Dulloo et al. (2004) are sensitive to both desiccation and low temperatures and cannot be stored at low temperatures for long periods of time. Furthermore, technical limitations in seed handling, storage and seedling production are the main problems encountered in promoting these species (Omondi, 2004). There is always need for storage of planting materials between the time of collection and planting. This may be due to the need to transport the materials from collection point to where it will be planted. Also, there may be need to store seeds till the subsequent growing season in environments with distinct dry or winter period when plants can hardly grow on the field naturally.

Understanding seed drying and storage behaviour can help ensure a better handling and storage of these seeds, and hence the availability of these resources for livelihoods (Dulloo et al., 2004). Recalcitrant seeds should be planted immediately after collection or stored under special conditions to ensure their viability at the time of planting. Adeleke and Abiodun (2010) stated that breadnut seeds have low organic acid which denote the keeping quality of the seeds, hence, the seeds need to be processed to avoid spoilage and wastage during its season. NTBG (2016) also recommended that the seeds should be sowed immediately after collection because the seeds lose viability (ability to sprout and grow) within a few weeks because the seeds cannot be stored and are damaged by chilling or drying. However, there is no adequate information on the actual number of days the seeds can remain viable after maturity (dropping off from the tree) when stored at room temperature or in refrigerator at $4^{\circ} \mathrm{C}$ in rainforest zone of Nigeria where breadnut trees are mostly found. The objective of this study was therefore to determine the effect of different storage methods and duration on viability of breadnuts in rainforest agroecology of Nigeria.

\section{MATERIALS AND METHODS}

\section{Materials}

Breadnut fruits used in this investigation were picked about 24 to $48 \mathrm{~h}$ after they fell off the trees at Ifewara, Osun State, South-west Nigeria. According to RobertsNkrumah (2005), the best fruits for propagation are full ripe ones which have turned brown and fall off the tree for themselves or are ready to do so. The fruits were immediately transported to the Plant Breeding Laboratory, Department of Agronomy, University of Ibadan where the storage study was carried out. Ifewara and Ibadan are in the same agroecology. The seeds were extracted from the fruits in the laboratory and were at that point regarded as fresh since according to FAO (2012), the seeds can be left in the fruit for about two days if it is not possible to plant them immediately. The seeds were removed from the pulp of the fruit and cleaned carefully to ensure no injury to any part of the seeds, most especially the young seedlings. Following the recommendation by Roberts-Nkrumah (2005), only full size and well-formed seeds (those with split endocarp and a light green "pouch-like" structure which contains the young seedlings) were selected for this study. The storage experiment was carried out in the laboratory using refrigerator $\left(4^{\circ} \mathrm{C}\right.$ ) (to investigate if the seeds could be stored for a short period at low temperature) and open shelf at ambient temperature $\left(22\right.$ to $\left.34^{\circ} \mathrm{C}\right)$. Polybags measuring 13.5 in width and $24 \mathrm{~cm}$ in height were used for the germination test in the greenhouse of Department of Agronomy, University of Ibadan.

\section{Storage and germination tests}

The storage and germination tests were carried out in two seasons (May to July, 2014 and November 2015 to January 2016) to investigate the effect of storage condition (temperature) and duration on germinability of the seeds. The storage test was a $3 \times 2$ (three storage periods and two storage methods) factorial experiment laid out in randomized complete block design with four replicates of 30 seeds. The storage methods used were refrigerator, open shelf and check (no storage), that is, fresh seeds planted immediately after processing of the seeds at lbadan.

In each season, 120 seeds were planted as fresh and 240 seeds were stored using each medium. Weight of the seeds stored using open shelf was taken at the beginning of the storage experiment and at 1 and 2 weeks after storage (WAS) in the first season using randomly selected 9 seeds per rep. The same sets of seeds were used each time in the four replications. In the first season, half (120) of the seeds stored using each method were sown in the nursery at 2 weeks while the remaining half were sown 4 WAS in 4 replicates of 30 seeds to determine the viability after storage. Having realised zero germinability in the first season, the total duration of storage was reduced to 2 weeks in the second season whereby half of the seeds were removed from storage for viability test at 1 WAS while the remaining half were tested at 2 WAS. 
Table 1. Mean monthly temperature and relative humidity at Ibadan, Nigeria.

\begin{tabular}{lccc}
\hline \multirow{2}{*}{ Month } & \multicolumn{2}{c}{ Temperature $\left({ }^{\circ} \mathbf{C}\right)$} & \multirow{2}{*}{ Relative humidity (\%) } \\
\cline { 2 - 3 } & Minimum & Maximum & 66 \\
January & 21.2 & 33.1 & 67 \\
February & 23.0 & 34.6 & 71 \\
March & 23.6 & 34.3 & 77 \\
April & 23.3 & 32.9 & 80 \\
May & 22.8 & 31.7 & 82 \\
June & 22.2 & 29.9 & 84 \\
July & 21.9 & 28.2 & 83 \\
August & 21.5 & 27.9 & 83 \\
September & 21.7 & 28.8 & 82 \\
October & 21.9 & 30.1 & 77 \\
November & 22.3 & 32.1 & 70 \\
December & 21.4 & 32.2 & \\
\hline
\end{tabular}

Source: https://www.weather2visit.com/africa/nigeria/ibadan.

\section{Sowing of seeds}

The propagation polythene bags with holes at the bottom were filled with about $1 \mathrm{~kg}$ of topsoil collected from an undisturbed site to within 2 to $3 \mathrm{~cm}$ from the top. The soil mixture was thoroughly watered until water drained from the bag. A hole was made in the soil at the centre of each bag, the depth of which was about twice the length of the seed. One seed was positioned in an upright position in each bag with the slit (opening on the endocarp through which the young seedling emerges) towards the centre of the hole and the seed was covered with the soil. The bags were arranged on a bench in the greenhouse under light shade and ambient conditions (Table 1). The bags were watered as necessary taking care to avoid both over watering and drying out and seedling emergence was recorded on daily basis until the experiment was terminated.

\section{Data collection and analysis}

Data were collected on weight of fresh seeds before storage on open shelf and at 1 and 2 WAS in the first season. In the greenhouse (germination test experiment), number of emerged seedlings was recorded on daily basis and the data were used to estimate the percent germinability of the seeds. The data were subjected to descriptive analysis using Microsoft excel software and analysis of variance (ANOVA) using SAS software (version 9.0).

\section{RESULTS}

The external appearance of the seeds after each storage period was not quite different from that of the fresh fruits except for some level of dryness observed in the seeds stored on the shelf (Figure 1). Also, the pouch-like structures (P-LS) containing the young seedlings of the stored seeds under the two methods were rusty (dark brown in colour) after storage indicating death of the young seedlings unlike that of fresh fruits which was light green in colour. This was observed from the first week after storage (WAS). While the seeds stored using the two methods remained almost intact physically before opening apart from the rustic P-LS (Figure 1), it was observed that the cotyledons were decayed under the two storage methods, most especially the seeds stored in the refrigerator and some level of shrinking of the testa was observed among the seeds stored on open shelf obviously due to loss of moisture (Figure 2).

There was significant reduction in weight of seeds stored on the open shelf over the period of the storage experiment except seed number 35 which had a weight of 2.213 and $2.035 \mathrm{~g}$ at 1 and 2 WAS, respectively (Figure 3 ). The trend of weight reduction resulting mostly from loss of moisture over time among the seeds followed almost the same pattern. The average seed weight of the fresh seeds was $6.30 \mathrm{~g}$ with a range of 4.85 to $7.83 \mathrm{~g}$ while at 1 and 2 WAS, the average seed weight reduced to 4.19 and $2.88 \mathrm{~g}$, respectively (Table 2 ). This on average translated to about $34 \%$ weight loss among the seeds at one week after storage (WAS) while 54\% weight loss was recorded at 2 WAS. Standard deviation was slightly lower $(0.63)$ at 1 WAS than the observed value of 0.7 among the fresh seeds. However, the standard deviation at 2 WAS was almost half of what was observed at 1 WAS indicating more loss in weight among the larger seeds between the first and second weeks. Low coefficient of variation ranging between 11 and $15 \%$ was observed among the seeds across the storage period.

All the stored seeds (either on open shelf or in refrigerator) 


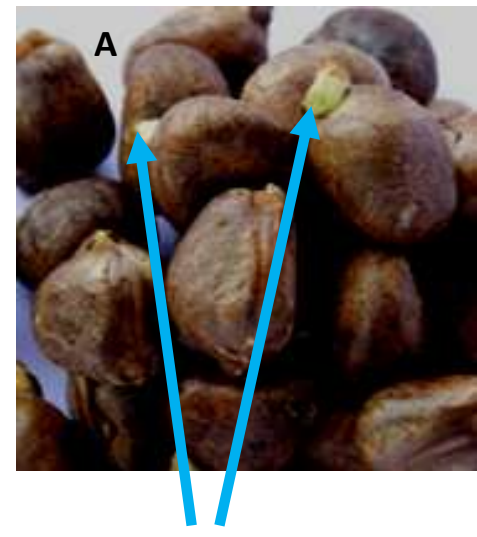

Light green "pouch-like" structure

which contains living young seedling

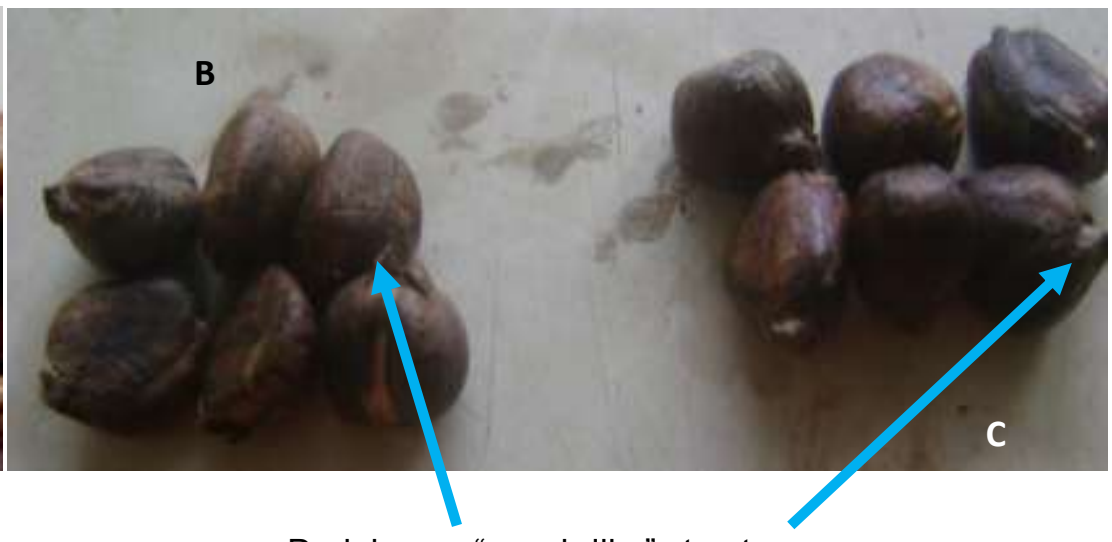

Dark brown "pouch-like" structures

which contains the dead young seedling

Figure 1. Physical features of fresh (A) breadnuts and those stored using open shelf $(B)$ and refrigerator (C) 2 weeks after sowing. Source of A: C. Nelson (https://www.google.com).

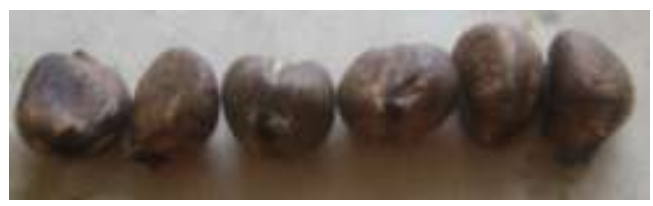

Open shelf (2 WAS)

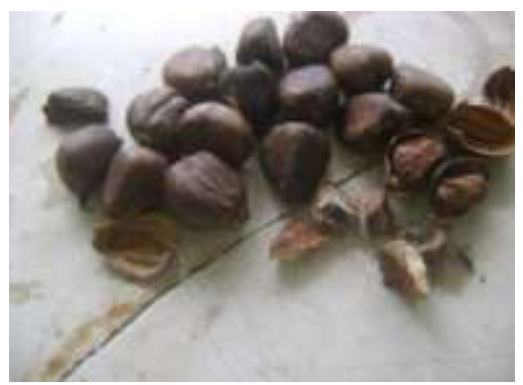

Open shelf (4WAS)

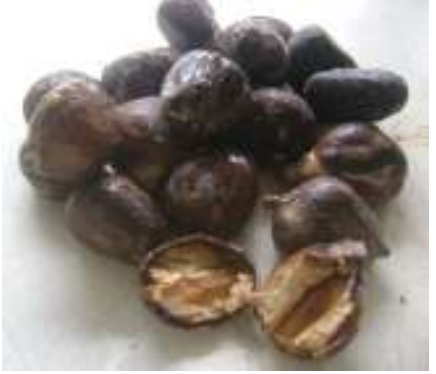

Refrigerator (4WAS)

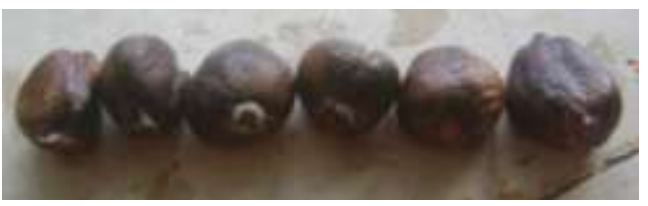

Refrigerator (2 WAS)

Figure 2. Physical features of breadnut seeds and cotyledons at different storage period using two storage methods (WAS $=$ weeks after sowing).

lost their viability regardless of the period of storage as no germination was recorded when the seeds were sowed in the greenhouse. The percent germinability of the fresh seeds ranged between 60 and 73 in the first season and between 63 and 77 in the second season with average of 67 and 72 in the first and second seasons, respectively (Table 3 ). There was no significant effect of season on germinability of breadnut seeds in this study (Table 4).

\section{DISCUSSION}

The high standard deviation observed for weight of the breadnut seeds when fresh and at 1 WAS compared to the value at 2 WAS (almost half of what was observed at 1 WAS) indicates that there was more loss in weight among the larger seeds between the first and second weeks compared to the smaller seeds. The similar variation in seed weight observed across the storage period in this study indicates that the rate of weight loss among the seeds is almost constant over time. This is further corroborated by the rate of loss in weight of the individual seeds over the storage period. This understanding of seed drying and storage behaviour can therefore help to ensure a better handling and storage of the seeds (Dulloo et al., 2004). The observed similar trend of weight reduction over time among the seeds 


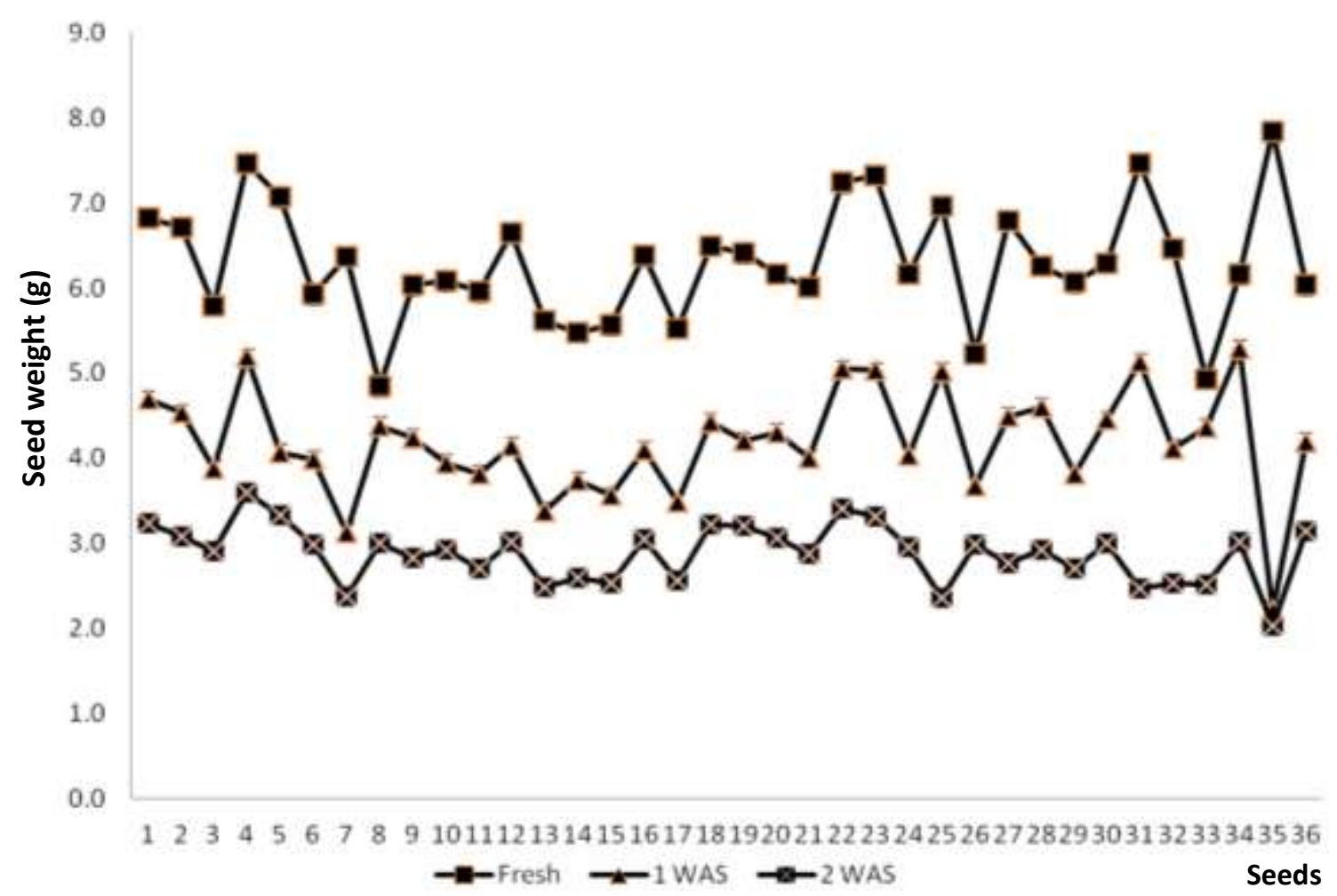

Figure 3. Effect of storage period on the weight of breadnut seeds stored using open shelf method. WAS: Weeks after storage.

Table 2. Statistical summary of weight $(\mathrm{g})$ of breadnut seeds stored using open shelf method at different storage period.

\begin{tabular}{lccc}
\hline Parameter & Fresh seeds & 1 Week After Storage & 2 Weeks After Storage \\
\hline Mean & 6.30 & 4.19 & 2.88 \\
Range & $4.85-7.83$ & $2.21-5.29$ & $2.04-3.59$ \\
St dev & 0.70 & 0.63 & 0.34 \\
CV $(\%)$ & 11.16 & 14.94 & 11.73 \\
\hline
\end{tabular}

Table 3. Percent germinability among fresh breadnut seeds sowed in two seasons (2014 and 2015) at Ibadan, Nigeria.

\begin{tabular}{lcc}
\hline Replication & $\mathbf{2 0 1 4}$ & $\mathbf{2 0 1 5}$ \\
\hline 1 & 60 & 63 \\
2 & 70 & 70 \\
3 & 63 & 77 \\
4 & 73 & 77 \\
Average & 67 & 72 \\
LSD (season) & \multicolumn{2}{c}{9.67} \\
\hline
\end{tabular}

indicates that there may be no much variation in rate of seed weight loss in breadnut, hence, selection for this trait may be difficult.

The little difference observed in this study between the fresh and stored seeds in terms of external appearance despite rotting of the cotyledons and shrinking of testa of the seeds in storage suggests that external attributes alone should not be used as indicators for selecting edible and viable seeds. Therefore, growers should ensure that only germinating seeds (Roberts-Nkrumah, 2005) with living (green) young seedlings are sourced from suppliers since this indicates that the seeds are still alive. Also, consumers buying seeds with rusty sprouts should break some randomly picked seeds from the lot to ensure the cotyledons are still edible. The significant reduction in weight of seeds stored on the open shelf over duration of this study indicates loss of moisture and some of the food assimilates in the seeds over time and the fact that an appreciable weight loss was recorded within a week indicates that the seed is highly unmanageable, an attribute of a recalcitrant seed (Dulloo et al., 2004). However, there is need to further investigate 
Table 4. Analysis of variance for seed germinability of fresh breadnut in two seasons at Ibadan, Nigeria.

\begin{tabular}{lccccc}
\hline Source & Degree of freedom & Sum of Squares & Mean square & F value & Pr $>$ F \\
\hline Season & 1 & 4.5 & 4.50 & 3.00 & 0.1817 \\
Rep & 3 & 16.5 & 5.50 & 3.67 & 0.1571 \\
Error & 3 & 4.5 & 1.50 & & \\
Corrected total & 7 & 25.50 & & & \\
\hline
\end{tabular}

the type of food assimilates lost in breadnut seeds during the storage period and the rate of loss of each of the assimilates. Loss of viability by all the stored seeds (either on open shelf or in refrigerator) regardless of the period of storage recorded in this study corroborates earlier submissions that the seeds lose viability within a few weeks because the seeds cannot be stored and are damaged by chilling or drying (Morton, 1987; FAO 2012; NTBG, 2016). However, the actual period of storage to ensure viability of the seeds using different storage methods is yet to be established.

High percent germinability recorded for the fresh seeds in the two seasons indicates that huge success can be achieved in propagation of breadnut if the seeds are sown immediately after extraction from the fruits. The fact that no special treatments other than normal propagation procedures were adopted in this study indicates that farmers can easily propagate this crop on their farms using their traditional farming techniques. Non seasonal effect on the germinability recorded in this study despite carrying out the studies at different periods of the year suggests that farmers may decide to propagate this crop at any period of the year the seeds are available as will fit into the growing season in each region.

\section{CONCLUSION AND RECOMMENDATIONS}

To determine the effect of storage methods and period on germinability of breadnut seeds, this study was carried out at Ibadan, Nigeria in 2014, 2015 and 2016. Total loss of viability among all the seeds stored even over the shortest storage period (one week) in this study calls for need to establish the number of days for which breadnut seeds can be stored using refrigeration and open shelf before they lose viability. Also, there is need for further studies on storability of breadnut seeds using other storage media to identify the methods by which breadnut seeds can be preserved and the duration of such storage should be determined. Farmers and consumers should not purchase or collect seeds based on external appearance of the endocarp alone but the status of the sprouts (for cultivation) and the cotyledons (for consumption) should be determined before procurement. Until reliable storage method for breadnut is discovered, it is recommended that farmers should sow the seeds immediately after collection and extraction from the fruit while consumers should process the seeds immediately after procurement. Also, farmers who cannot afford to sow the seeds immediately should ensure they are not extracted from the fruit until the time of sowing as past investigation has revealed that the seeds remain viable for about two days in such condition (FAO, 2012).

\section{ACKNOWLEDGEMENTS}

Efforts of Deacon Olakanmi Olasanmi and Mr. Kehinde Adegoke who assisted with the seed collection, transportation and activities in the nursery are acknowledged.

\section{REFERENCES}

Adeleke RO, Abiodun OA (2010). Nutritional composition of breadnut seeds (Artocarpus camansi). Afr. J. Agric. Res. 5(11):1273-1276.

African Orphan Crops Consortium (AOCC) (2013). Healthy Africa through nutritious, diverse and local food crops. http://africanorphancrops.org/meet-the-crops/. Accessed 25 October, 2016.

American Phytopathological Society (APS) (2016). Phytobiomes: A Roadmap for Research and Translation. Phytopathol. News 50(3):2942.

Dulloo ME, Jøker D, Thomsen KA, Amaral WAN (2004). General Introduction. In: Storage Biology of Tropical Tree Seeds. Sacandé M, Jøker D, Dulloo ME, Thomsen KA (eds.). pp. 363.

Food and Agriculture Organization of the United Nations (FAO) (2012). Breadnut and breadfruit propagation, a manual for commercial propagation. p. 28.

Morton J (1987). Breadfruit. In: Fruits of warm climates. Julia F. Morton, Miami, FL. p. 50-58. https://www.hort.purdue.edu/newcrop/morton/breadfruit.html. Accessed 20 August, 2016.

National Tropical Botanical Garden (2016). Breadfruit. http://ntbg.org/breadfruit/breadfruit/propagation1.php. Accessed 25 August, 2016.

Nelson C (2017). Breadnut Definition, History and Nutritional Value: Cooking with Breadnuts. https://www.thespruce.com/all-aboutbreadnut-2137936. Accessed 7 February, 2018.

Omondi W (2004). Desiccation sensitivity of seeds of four tree species of economic importance in Kenya. In: Storage Biology of Tropical Tree Seeds. Sacandé M, Jøker D, Dulloo ME, Thomsen KA (eds.). pp. 363.

Roberts-Nkrumah LB (2005). Fruit and seed yields in chataigne (Artocarpus camansi Blanco) in Trinidad and Tobago. Fruits 60(6):387-393. 